\title{
La amplitud de PPG está bien correlacionada con los cambios latido a latido en la TA y en la impedancia vascular
}

\author{
Rudzik NM. ${ }^{1}$, Santanera B. ${ }^{1}$, Viotti FJ. ${ }^{1}$, Portela F. ${ }^{1}$, Gerez SA. ${ }^{1}$, Venturin N. ${ }^{1}$, Acosta CM. ${ }^{1}$, Tusman G. ${ }^{1}$ \\ 1 HPC, Mar del Plata, Argentina.
}

Introducción: Correlacionar el comportamiento fisiopatológico de la amplitud de la fotopletismografía (PPG) con la presión de pulso (PP) y la compliance vascular (C vasc) latido a latido, como parte del monitoreo hemodinámico no invasivo en pacientes quirúrgicos.

Materiales y Métodos: Fueron estudiados 23 pacientes bajo anestesia general. La amplitud de la PPG, la presión de pulso (PP) y la compliance vascular (dV/dP calculada desde las señales de PPG y PP) fueron registradas durante cambios en la presión arterial. El RI (índice de resistividad) y la Vm (velocidad media) se midieron con el Doppler de la arteria radial (técnica snuff box) en cada episodio hemodinámico.

El análisis se realizó de la siguiente manera: 1) se seleccionaron 20 latidos en cada episodio de hiper-normo-hipotensión arterial en cada paciente. La información hemodinámica, PPG e índices RI-Vm del análisis Doppler constituyó la base de datos de todos los pacientes; 2) La amplitud de la PPG fue correlacionada con la PP y la Cvasc, latido a latido, durante 5-15\&apos; de registro.

Resultados: Los principales resultados se observan en la tabla. Se detectaron 111 episodios de cambio en la presión arterial de los pacientes. La amplitud de la PPG disminuyó en un 38\% durante la HTA $(p=0,0001)$ y se incrementó un $25 \%$ durante la hipotensión $(\mathrm{p}=0,0205)$ cuando se comparó con la normotensión. En la HTA se evidenció alta PP y en la hipotensión, baja PP (ambas con $\mathrm{p}<0,001$ ) comparadas con la normotensión. El RI no mostró diferencia estadísticamente significativa en las diferentes cifras de TA. La Vm fue diferente entre los distintos valores de presión arterial, aumentando con la vasodilatación. Las correlaciones individuales entre la amplitud de la PPG vs PP (mediana $-0,90$, 1 er-3er cuartilos $-0,93$ y $-0,80$ ) y Cvasc (mediana 0,95 , 1 er-3er cuartilos 0,93 y 0,8 ) fueron estadísticamente significativas.

Conclusiones: La amplitud de la PPG estuvo bien correlacionada con la PP y la Cvasc latido a latido. Ambas señales (amplitud PPG y PP), varían en forma opuesta cuando se altera la Cvasc, modificando la forma y la velocidad en la que la onda de pulso, de flujo y presión, viajan a lo largo del árbol vascular. Este comportamiento fisiopatológico tiene importantes implicaciones clínicas para el monitoreo hemodinámico no invasivo en pacientes quirúrgicos.

https://doi.org/10.25237/congresoclasa2019.55 